University of Nebraska - Lincoln

DigitalCommons@University of Nebraska - Lincoln

Faculty Papers and Publications in Animal

Science

Animal Science Department

2009

\title{
BOARD-INVITED REVIEW: Porcine mucosal immunity of the gastrointestinal tract
}

Thomas E. Burkey

University of Nebraska-Lincoln, tburkey2@unl.edu

K. A. Skjolaas

Talecris Biotherapeutics

J. E. Minton

Kansas State University

Follow this and additional works at: https://digitalcommons.unl.edu/animalscifacpub

Part of the Animal Sciences Commons

Burkey, Thomas E.; Skjolaas, K. A.; and Minton, J. E., "BOARD-INVITED REVIEW: Porcine mucosal immunity of the gastrointestinal tract" (2009). Faculty Papers and Publications in Animal Science. 699.

https://digitalcommons.unl.edu/animalscifacpub/699

This Article is brought to you for free and open access by the Animal Science Department at DigitalCommons@University of Nebraska - Lincoln. It has been accepted for inclusion in Faculty Papers and Publications in Animal Science by an authorized administrator of DigitalCommons@University of Nebraska - Lincoln. 


\title{
BOARD-INVITED REVIEW: Porcine mucosal immunity of the gastrointestinal tract ${ }^{1}$
}

\author{
T. E. Burkey, ${ }^{2}$ K. A. Skjolaas, $\dagger$ and J. E. Minton $\ddagger$ \\ *Department of Animal Science, University of Nebraska, Lincoln 68583; †Talecris Biotherapeutics, \\ Research Triangle Park, NC 27709; and $\ddagger$ Department of Animal Sciences and Industry, \\ Kansas State University, Manhattan 66506
}

\begin{abstract}
The gastrointestinal tract (GIT) constitutes one of the largest immunological organs of the body. The GIT must permit absorption of nutrients while also maintaining the ability to respond appropriately to a diverse milieu of dietary and microbial antigenic components. Because of the diverse population of antigenic components within the GIT, a sophisticated mucosal immune system has evolved that relies on collaboration between the innate and adaptive arms of immunity. The collaborative, mucosal immune effort of-
\end{abstract}

fers protection from harmful pathogens while also being tolerant of dietary antigens and normal microbial flora. Knowledge with respect to porcine mucosal immunity is important as we strive to understand the interrelationships among GIT physiology, immunology, and the resident microbiota. The aim of this review is to provide a descriptive overview of GIT immunity and components of the mucosal immune system and to highlight differences that exist between the porcine species and other mammals.

Key words: gut-associated lymphoid tissue, intestinal epithelial cell, mucosal immunity, pig

(C)2009 American Society of Animal Science. All rights reserved.

J. Anim. Sci. 2009. 87:1493-1501

doi:10.2527/jas.2008-1330

\section{INTRODUCTION}

One of the major functions of the immune system is to identify and eliminate pathogens; however, with respect to immune function within the gastrointestinal tract (GIT), it may be equally important to achieve a homeostatic balance between immune tolerance and immune responsiveness (Artis, 2008). In vertebrates, the immune system is subdivided into the innate and adaptive arms of immunity. In a broad sense, the innate immune system is composed of anatomic, physiologic, phagocytic, and inflammatory barriers (Goldsby et al., 2003). The aforementioned barriers enable the innate immune system to provide the first line of defense against infectious disease. Innate immune components also interact extensively with adaptive components to help direct the adaptive immune response, which is characterized by a response to specific antigens and by immunologic memory. Because of the vast surface area

\footnotetext{
${ }^{1}$ A contribution of the University of Nebraska Agricultural Research Division, supported in part by funds provided through the Hatch Act and 09-025-J of the Kansas Agricultural Experiment Station (Manhattan).

${ }^{2}$ Corresponding author: tburkey2@unl.edu

Received July 24, 2008.

Accepted November 17, 2008.
}

of the GIT and the constant exposure to commensal and pathogenic microorganisms, mucosal immunity of the GIT has been the subject of great interest for the past several years.

The mucosal surface of the GIT forms an intricate collaboration with the intestinal lumen. The diverse milieu of antigenic dietary components, as well as the various populations of microbes within the GIT, has facilitated the need for an evolving and sophisticated mucosal immune system. Much of the burden on mucosal immunity is shouldered by intestinal epithelial cells (IEC). The IEC monolayer provides anatomic and physiologic barriers designed to maintain homeostasis within the GIT. Taken together, along with the idea that the GIT must fulfill its primary absorptive function, it is imperative that the mucosal immune system of the gut effectively discriminate and respond appropriately to enteropathogens as well as harmless food antigens or antigens from commensal organisms. Failure to deal appropriately with antigenic stimuli can result in chronic inflammation, decreased digestive function, and a decreased rate of growth.

The importance of mucosal immunity is clear when one considers that the gut contains greater than $10^{12}$ lymphocytes and has a greater concentration of antibodies than any other site in the body (Mayer, 2000). The mucosal immune system is adequately equipped to generate a protective immune response directed at 
harmful pathogens, but it also has the capability to be tolerant of the ubiquitous dietary antigens and normal microbial flora while maintaining the ability to permit the absorption of nutrients. In addition to thorough reviews of the mammalian gastrointestinal immune system (James, 1993; Kagnoff, 1993; Par, 2000; Brandtzaeg and Pabst, 2004), reviews have also been published regarding the porcine immune system (Blecha, 2001; Scharek and Tedin, 2007), as well as reviews specific to the porcine gastrointestinal immune system (Mayrhofer, 1984; Stokes et al., 1994, 2001). In addition, researchers have begun to use genomics-based approaches to further our knowledge of immunity in the porcine gut (Dvorak et al., 2006). Therefore, the aim of this review is to provide a description of mucosal immunity and components of the mucosal immune system in swine and to highlight differences between swine and other mammalian mucosal immune systems.

\section{MUCOSAL IMMUNITY}

Confronted with a large array of antigens, the immune system faces a considerable challenge in its efforts to maintain local tissue homeostasis in the intestinal mucosa. For example, at least 400 different species of bacteria contribute to a total of approximately $10^{14}$ microbes that are distributed throughout the GIT (Gorbach et al., 1967; Suau et al., 1999). The mucosal immune system must prevent the dissemination and proliferation of these potentially harmful microbes while sparing the vital structures and function of the intestine. To carry out this daunting task, the intestinal mucosa, complete with a single layer of epithelial cells, provides a barrier to the commensal and pathogenic bacteria present within the gastrointestinal milieu (Neutra et al., 2001). In addition to the physical barrier that the epithelia provide, the mucosal immune system also uses other gut-associated lymphoid tissues (GALT) to protect the organism and to mediate subsequent innate and adaptive immune responses. A hallmark of mucosal immunity is the induction of an immune response in Peyer's patches and the subsequent production of secretory IgA by B lymphocytes in the lamina propria. The importance of interactions among the microbiota, the gut epithelium, and the GALT were emphasized by Falk et al. (1998), who suggested that an important "trialogue" exists among these components that shapes the intestinal ecosystem.

The communication within the mucosal immune system is carried out by a large and highly specialized collection of tissues and cells within the GIT. In fact, the intestine is considered to be the largest lymphoid organ and contains more immune cells than any other organ, including the spleen and liver (Brandtzaeg et al., 1989). Immune cells within the GIT are highly compartmentalized within GALT and are described in the following sections.

\section{$G A L T$}

Gut-associated lymphoid tissue provides specific host defense and encompasses the largest collection of immune cells in the body (Mowat and Viney, 1997). The GALT is the focal point of the mucosal immune system and is generally divided into functional compartments known as inductive or effector sites (Brandtzaeg and Pabst, 2004). Inductive sites include areas of antigen sampling at mucosal surfaces, and effector sites include areas where lymphocytes differentiate and defend the organism in an immune response (Brandtzaeg and Pabst, 2004). There is some discrepancy regarding the classification of the structures and tissues that compose the GALT because there is no absolute distinction among the functional compartments. For the purpose of this review, we will consider the inductive portion of the GALT as comprising the appendix, isolated lymphoid follicles, and Peyer's patches (Brandtzaeg and Pabst, 2004). The lamina propria is generally considered an effector site within the GALT and is referred to as a compartment containing cells outside the Peyer's patches (Nagler-Anderson, 2001).

In general, GALT represents a site where $\mathrm{B}$ and $\mathrm{T}$ lymphocytes interact with intestinal antigens. However, before antigens reach the GALT, antigens must breach the IEC monolayer that separates the GALT from the intestinal lumen. The IEC monolayer provides both intrinsic and extrinsic barriers to potentially harmful pathogens and antigens (reviewed by Pitman and Blumberg, 2000). The intrinsic mechanism hinges on the establishment of a physical barrier via the highly organized IEC monolayer, which facilitates selective transfer of lumenal contents to the underlying GALT. Epithelial cells that line mucosal surfaces also function extrinsically by secreting proteins (e.g., mucins, antimicrobial peptides, and immunoglobulins) that limit the interaction of potential pathogens with the gut mucosa (Oswald, 2006). However, antigens and pathogenic microorganisms routinely circumvent the physical barrier provided by IEC. For example, antigen may be taken up by microfold ( $\mathbf{M})$ cells found within the follicle-associated epithelium of Peyer's patches (Tyrer et al., 2006). In addition, antigen may be sampled directly by dendritic cells, which open tight junctions between IEC to extend dendrites into the intestinal lumen (Rescigno et al., 2001), and certain species of bacteria overcome the epithelial barrier by using specialized invasion strategies such as the Type III secretion system (Hapfelmeier et al., 2005). Pathogens and other antigens within the gut lumen that traverse the IEC barrier eventually interact with phagocytic cells (e.g., macrophages and dendritic cells) as well as B and T lymphocytes within the GALT. These interactions provide the necessary signals for the initiation of an adaptive immune response and the generation of effector mechanisms (Pasare and Medzhitov, 2005). Effector cells then proceed to the mesenteric lymph nodes, 
where the immune response is amplified (Bode et al., 2002). Activated lymphocytes are then passed into the bloodstream via the thoracic duct and travel to the gut to carry out their specific effector functions. Taken together, the IEC monolayer and GALT combine to initiate and carry out innate and adaptive immune responses. In the following sections, GALT inductive and effector sites are considered; where possible, emphasis focuses on their functional significance and specific attributes as these apply to the domestic pig.

\section{GALT Inductive Sites}

Appendix and Cecum. Considered as the beginning of the large intestine and part of the colon, the cecum is a pouch-like structure at the end of the small intestine that is separated from the ileum by the ileocecal valve. The appendix, similar in structure and form to the cecum, is a diverticulum that extends from the cecum. The appendix is highly vascular, is lymphoid rich, and produces immune cells that are normally attributed to the GALT (Spencer et al., 1985; Somekh et al., 2000). It has been hypothesized that the appendix may have exocrine, endocrine, and neuromuscular functions. However, limited evidence suggests that the most likely function of the appendix is as part of the gastrointestinal immune system (Dasso and Howell, 1997; Shanahan and O'Sullivan, 1997; Pospisil and Mage, 1998). Hypothesized functions attributed to the appendix have not been proven unequivocally, and the most prominent functional period of the appendix probably exists in the developing fetus and the neonatal animal (Dasso et al., 2000). In the domestic pig, the significance of the appendix becomes irrelevant because the appendix cannot be found within the porcine gastrointestinal anatomy (Simic and Ilic, 1976; Schantz et al., 1996).

Peyer's Patches. Islands of discrete, organized lymphoid tissue with areas populated by B and T lymphocytes located in the small intestine are known as Peyer's patches and have been thoroughly reviewed elsewhere (Mayrhofer, 1984; Heel et al., 1997; Makala et al., 2002). Unlike the adjacent absorptive epithelium, Peyer's patches are overlaid with a specialized follicle-associated epithelium. The follicle-associated epithelium has a filamentous brush border glycocalyx but lacks the membrane-associated hydrolytic enzymes characteristic of the absorptive epithelium (Neutra et al., 2001). In addition, the follicle-associated epithelium harbors specialized antigen-sampling $M$ cells that are interdigitated within the epithelium (Owen and Jones, 1974). Immune surveillance of the GIT is an important function of M cells (Gewirtz and Madara, 2001; Neutra et al., 2001). Underlying the follicle-associated epithelium, large B-cell follicles and adjacent T-cell areas surround a germinal center supported by follicular dendritic cells. Generally speaking, Peyer's patches are sites of antigen sampling and have a role in the induction of mucosal immune responses. However, differences among Peyer's patch development, structure, and func- tion between species have been reported (Griebel and Hein, 1996; Andersen et al., 1999).

Peyer's patches have been described in the domestic pig and are known to reside in the small (jejunum and ileum) and large (spiral colon) intestine (Chu and Liu, 1984; Binns and Licence, 1985; Lowden and Heath, 1994). Within the small intestine of pigs, discrete Peyer's patches are found in the jejunum and upper ileum, and a continuous Peyer's patch is evident along the terminal ileum (Rothkotter et al., 1990). Even though ileal and jejunal Peyer's patches are morphologically similar, Pabst et al. (1988) concluded that there is a greater lymphocyte production rate, a greater number of total germinal follicles, and a greater mean follicle diameter in ileal Peyer's patches compared with jejunal Peyer's patches. In addition, although human and mouse ileal Peyer's patches have been established as secondary lymphoid organs, there is evidence to suggest that ileal Peyer's patches in sheep, cattle, and swine exhibit properties consistent with a function as primary B-cell lymphoid organs (Reynolds, 1987; Parng et al., 1996; Andersen et al., 1999). Considering the species differences, differences in $\mathrm{B}$ and $\mathrm{T}$ lymphocyte distribution, quantity, and function, the Peyer's patch is a complex lymphoid aggregate that has multiple functions. The Peyer's patch decreases antigen translocation across the mucosal epithelium via selective uptake by $\mathrm{M}$ cells, and helps to recognize luminal antigen to direct subsequent immunological responses. The role of $\mathrm{M}$ cells in microbial recognition has not been fully elucidated because of difficulties in establishing suitable in vitro models, but recent work has provided some insight into M-cell function. For example, Tyrer et al. (2006) has provided evidence that pattern recognition receptors (e.g., Tolllike receptors) are important for M-cell recognition of Gram-negative bacteria and to induce an appropriate mucosal immune response. Because the in vitro model established by this group consisted of human epithelial cells cocultured with murine Peyer's patch cells, these observations may not be applicable to swine. Even so, recent observations by Shimosato et al. (2005) and Tohno et al. (2005) provided evidence that Toll-like receptors are expressed on porcine $\mathrm{M}$ cells and contribute to ligand-specific transcytosis, which is consistent with the hypothesis that Peyer's patches may be responsible for the induction of immune responses.

Isolated Lymphoid Follicles and Cryptopatches. Isolated lymphoid follicles are lymphoid aggregates in the antimesenteric wall of the small intestine that have been described in mice (Hamada et al., 2002) and humans (Moghaddami et al., 1998). Similar to Peyer's patches, isolated lymphoid follicles contain germinal centers with segregated B- and T-cell areas and an overlying follicle-associated epithelium complete with M cells (Hamada et al., 2002). Isolated lymphoid follicles function as inductive sites for antigen-specific mucosal immune responses (Lorenz and Newberry, 2004). Kanamori et al. (1996) described murine cryptopatches as small aggregates of lymphocytic cells in the 
basal lamina propria of the small and large intestine. This group also characterized the cells within cryptopatches as lineage negative and expressing the stem cell factor known as c-kit. Suzuki et al. (2000) has provided evidence that cryptopatches function as sites for the development of progenitor $\mathrm{T}$ cells for extrathymic intraepithelial lymphocyte descendants. More recently, Pabst et al. (2005) provided evidence that argued against separate, isolated lymphoid follicle and cryptopatch lymphoid aggregations. According to Pabst et al. (2005), cryptopatches have been identified only in mice and in their current work; no cryptopatch-like structures could be identified in the human, rat, or pig intestine.

\section{GALT Effector Sites}

Lamina Propria. Subsequent to immune induction, the lamina propria has proven to function as the regulator of immune responses in the intestine (Makala et al., 2001). The gastrointestinal lamina propria is composed of smooth muscle cells, fibroblasts, blood vessels, and lymphatics that make up a highly vascular layer of loose connective tissue underlying and supporting the mucosal epithelium (Hunyady et al., 2000). In addition, the lamina propria contains macrophages, dendritic cells, neutrophils, mast cells, and lymphocytes that participate in lamina propria effector functions (Hunyady et al., 2000). After induction in the Peyer's patch, mature $\mathrm{T}$ and $\mathrm{B}$ cells travel to the mesenteric lymph nodes via the lymphatic circulation before homing to the lamina propria (Hokari et al., 2001), where T cells can directly eliminate pathogens and where $\mathrm{T}$ and $\mathrm{B}$ cells can participate in the production of cytokines and immunoglobulins (e.g., IgA). A detailed discussion of the porcine lymphocyte repertoire and antibody development is not included in this review; however, please see Butler et al. (2006a,b) for excellent reviews on these aspects of porcine immunology. In humans, the majority of lamina propria $\mathrm{T}$ cells are $\mathrm{CD} 4^{+}$and express the aß T-cell receptor (Brandtzaeg et al., 1998). Lamina propria $\mathrm{T}$ cells differ from peripheral $\mathrm{T}$ cells in that they have a greater threshold of activation, produce increased concentrations of cytokines on stimulation, and have a phenotype associated with immunologic memory (Wittig and Zeitz, 2003). In addition, most species express CD25 and isoforms of CD45, which are consistent with antigen recognition and immunologic memory, respectively (Haverson et al., 1999). Between species, the population of lymphocytes that resides in the lamina propria has been classified as heterogeneous, and the organization of these cells is classified as random (Bailey et al., 2005). Collectively, these characteristics are consistent with the effector function of lamina propria lymphocytes, which enables these cells to participate in immunosurveillance and to respond actively to potential pathogens.

Important differences in lamina propria lymphocytes exist between humans and swine that may relate to the function of these compartmentalized cells. In the small intestine of pigs, lymphocytes have been categorized as diffuse or organized (Pabst and Rothkotter, 1999). As is the case for most species, intraepithelial lymphocytes and lymphocytes contained in the lamina propria are considered diffuse lymphocytes. In contrast, the gut mucosa of the pig has a greater degree of organization compared with the gut mucosa of rodents and humans (Bailey et al., 2001). For example, Vega-Lopez et al. (1993) observed that plasma cells are preferentially localized to the intestinal crypts and $\mathrm{T}$ cells to the intestinal villi. Vega-Lopez et al. (1993) also observed a spatial separation between $\mathrm{CD} 4^{+}$and $\mathrm{CD} 8^{+} \mathrm{T}$ cells within the lamina propria of intestinal villi. In addition, researchers have observed differences in cytokines secreted by activated porcine and murine lamina propria $\mathrm{T}$ lymphocytes compared with human lamina propria T lymphocytes (Harriman et al., 1992; Bailey et al., 1994). The significance of the differences that exist in pigs has not been fully elucidated. It has been suggested that lamina propria lymphocytes, in addition to their effector function, also have a role in immunoregulation (Bailey et al., 2001). However, the regulatory role of $\mathrm{T}$ cells in the intestinal mucosa has received little attention and is currently being investigated (Kaser et al., 2008).

Intraepithelial Lymphocytes. Intraepithelial lymphocytes (IEL) represent a large, heterogeneous subclass of $\mathrm{T}$ cells that are integrated in the epithelial layer of many tissues (reviewed by Mowat and Viney, 1997; Hayday et al., 2001). Functionally, lines of evidence have portrayed human and murine IEL as having cytolytic and immunoregulatory properties that can be summoned quickly to maintain epithelial integrity and to protect host tissues from infectious agents. Intraepithelial $\mathrm{T}$ lymphocytes can be differentiated from circulating and lamina propria T lymphocytes. For example, circulating $\mathrm{T}$ cells are subdivided into similar proportions of $\mathrm{CD}^{+}$and $\mathrm{CD} 8^{+} \mathrm{T}$-cell populations, whereas the majority of IEL are $\mathrm{CD} 8^{+}$(Gebert et al., 1996). In addition, IEL can be $\alpha \beta$ and $\gamma \delta$ T-cell receptor positive, with the $\gamma \delta^{+}$cells having abundant expression of

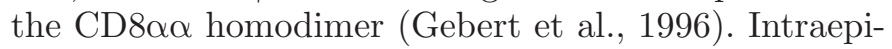
thelial lymphocytes also have a greater proportion of $\gamma \delta^{+}$cells compared with circulating concentrations in avian and murine species (Bucy et al., 1988; Goodman and Lefrancois, 1988). Another defining feature of IEL is their ability to bind to E cadherin on IEC, which is facilitated by the expression of $\alpha \mathrm{E} \beta 7$ integrin (Cepek et al., 1994). Researchers have also noted that characteristics such as morphology, size, and sedimentation density contribute to the heterogeneity of lymphocytes categorized as IEL (Hayday et al., 2001).

Because of this heterogeneity within IEL populations, Hayday et al. (2001) has proposed that IEL be classified into 2 subgroups: Type a and Type b. Intraepithelial lymphocytes that are thymus-dependent, activated within the peripheral circulation, that express the $\alpha \beta$ T-cell receptor, and that recognize antigen in 
the context of major histocompatability complex I or II would be included as Type a IEL. Type b IEL are thymus-independent cells that express T-cell receptors that are $\gamma \delta^{+}, \gamma \delta^{+} \mathrm{CD} 8 \alpha \alpha^{+}$, or $\alpha \beta^{+} \mathrm{CD} 8 \alpha \alpha^{+}$. Both types of IEL are cytolytic effectors that secrete cytokine and chemokine mediators. However, Hayday et al. (2001) concluded that Type a IEL are more indicative of an adaptive response, whereas Type b IEL are "revertants" to the innate immune response. The role of Type b IEL is also supported by evidence summarized by Havran et al. (2005) indicating that intraepithelial $\gamma \delta^{+} \mathrm{T}$ cells are involved in tissue repair, lysis of damaged epithelial cells, and inflammatory cell recruitment. Consistent with the heterogeneous nature of IEL, there is evidence to suggest that intraepithelial lymphocyte populations vary between species.

Similar to humans and mice, pig IEL express CD2 and have an increased proportion of $\mathrm{CD} 8^{+}$cells (Stokes et al., 2001). However, neonatal pigs are mostly $\mathrm{CD} 2^{-} \mathrm{CD} 4^{-} \mathrm{CD} 8^{-}$, and $\mathrm{CD} 8^{+}$IEL cannot be recognized until the animal matures. It has also been demonstrated that phenotypic changes in porcine IEL are influenced by exposure to environmental antigens (Pabst and Rothkotter, 1999). Vega-Lopez et al. (2001) observed similar developmental changes in IEL and proposed that the delayed maturation of IEL might be positively correlated with the increased disease susceptibility of young pigs. Even though there is more to learn about IEL, particularly in domestic animal species, their location among the intestinal epithelia is indicative of their importance as immune regulators and effectors at the luminal-epithelial interface.

\section{IEC as an Effector of Mucosal Immunity}

Kagnoff (1993) theorized that because of the diverse environment within the gut lumen, IEC have evolved mechanisms that constitute an effective anatomical and immunologically active barrier. One mechanism of the IEC barrier is the innate recognition and differentiation of commensal and pathogen-associated molecular patterns via pattern recognition receptors such as the Tolllike receptor family (Didierlaurent et al., 2002). Within the GIT, the IEC are compartmentalized, particularly in the small intestine, where different populations of IEC form a vertical crypt-villus axis (Turner, 2003). In most species, stem, goblet, secretory, enteroendocrine, and Paneth cells populate the crypt-villus axis. The intestinal villi comprise absorptive enterocytes and goblet cells, whereas Paneth cells can be found in the villus crypts. In addition to the primary absorptive function of IEC, within the GIT they must discriminate effectively and respond appropriately to food antigens as well as commensal and pathogenic microorganisms. Failure to deal with antigenic stimuli appropriately can result in chronic inflammation and decreased digestive function. Here we provide a brief review of IEC with specific emphasis on the immunological aspects of porcine epithelia.
Intestinal epithelial cells and intraepithelial lymphocytes constitute the epithelial layer of the intestine and are separated from the underlying lamina propria by the basal lamina. The crosstalk among the gut lumen, IEC, and the lamina propria provides the information that directs the mucosal immune system. In addition to the physical barrier that the IEC monolayer provides, Christ and Blumberg (1997) suggested that IEC have immunological functions that can be broadly categorized as follows: 1) secretion of soluble protein factors; 2) immunosurveillance; 3) regulators of immune responses; and 4) as targets for immune effectors. These immunological functions of the IEC monolayer are discussed further below.

A critical component of the barrier function attributed to the IEC monolayer is the formation of epithelial tight junctions (reviewed by Gumbiner, 1987; Shen and Turner, 2006). Tight junctions contribute to the highly selective IEC monolayer and participate in the polarization of the epithelial cell into apical and basolateral domains. Thus, the formation of tight junctions and the IEC monolayer is vitally important for separating the mucosa from lumenal components while allowing for the absorption of nutrients. In addition to tight junctions, barrier function is fortified by a mucinrich glycocalyx that lines the GIT and is embedded with antimicrobial peptides (Eckmann, 2004); however, the mucus layer has not been well characterized in the domestic pig. Therefore, the IEC monolayer, coated by mucus secreted from goblet cells, provides a nonspecific physical barrier that inhibits invasion by commensal and pathogenic bacteria that reside within the GIT.

In addition to the barrier function of IEC, they are considered prominent sources of soluble protein factors. For instance, secretion of chemokines and cytokines leads to the recruitment of macrophages, lymphocytes, and polymorphonuclear leukocytes and can therefore further initiate both the innate and adaptive immune responses (Eckmann et al., 1993; Jung et al., 1995; Maaser and Kagnoff, 2002). Interestingly, it is pathogenic bacteria, not commensal bacteria that trigger such inflammatory responses (Eckmann et al., 1997). Jung et al. (1995) demonstrated that after challenge with invasive (but not noninvasive) bacterial strains, human colon epithelial cell lines (T84, HT29, and Caco-2) expressed the proinflammatory cytokines IL8, monocyte chemotactic protein-1, granulocyte-macrophage colonystimulating factor, and tumor necrosis factor- $\alpha$. The porcine IEC line IPEC-J2 expresses mRNA for IL1 $\alpha$, IL6, IL7, IL12p40, IL18, tumor necrosis factor- $\alpha$, granulocyte-macrophage colony-stimulating factor, CCL20, macrophage migration-inhibiting factor, and osteopontin, and is also a prominent source of highly polarized IL-8 secretion (Schierack et al., 2005; Skjolaas et al., 2006). The central regulator involved in the IEC response to enteroinvasive bacterial pathogens is the signal transduction pathway, which includes I $\kappa$ B kinases and the downstream activation of the transcription fac-

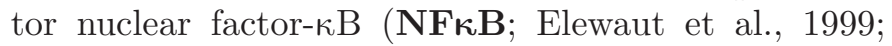


Gewirtz et al., 2000). The activation of NFkB culminates in the expression of mediators including, but not limited to, inflammatory cytokines. For instance, Hyland et al. (2006) observed that on administration of Salmonella serovar Choleraesuis, expression of CXCL2, IL-1 $\beta$, and IL- 8 mRNA is rapidly increased in porcine ileal Peyer's patches.

In addition to cytokines and chemokines, antimicrobial peptides are secreted by IEC (for a review, see Ganz, 2003). According to Ganz (2003), defensins are abundant in Paneth cells and are the most prominent group of antimicrobial peptides in humans. However, the presence of Paneth cells in pigs is debatable (Myer, 1982; Dekaney et al., 1997; Obremski et al., 2005). In swine, 13 isoforms of $\beta$-defensin have been characterized and are primarily of epithelial origin (Zhang et al., 1998; Sang et al., 2006). In addition to defensins, other antimicrobial peptides such as cathelicidins and protegrins, have been identified in swine and have been reviewed by Sang and Blecha (2008).

With respect to immunosurveillance, the synthesis and secretion of cytokines, chemokines, and antimicrobial peptides by IEC is dependent on the ability of IEC to decipher information received from the intestinal milieu. This role of IEC is largely accomplished via Toll-like receptors (Philpott et al., 2001; Takeda and Akira, 2003). In the porcine species, Toll-like receptors 1 through 10 have been characterized and reviewed elsewhere (Uenishi and Shinkai, 2008; Zhu et al., 2008). Recognition and detection of bacteria and bacterial products by Toll-like receptors initiates a signaling cascade that culminates in the activation of $\mathrm{NF}-\kappa \mathrm{B}$ and transcription of proinflammatory cytokines (Ghosh et al., 1998; Medzhitov et al., 1998). Similar to cytokine and chemokine mediators, the expression of antimicrobial peptides has also been linked to signaling via Toll-like receptors (Vora et al., 2004). The immunosurveillance role of IEC is not restricted to Toll-like receptors. Nucleotide-binding oligomerization domain (NOD)-like receptors are an additional family of pattern recognition receptors that detect pathogen-associated molecular patterns intracellularly (Meylan et al., 2006). Two NOD family receptors (NOD1 and NOD2) have been identified in pigs (Tohno et al., 2008a,b). In addition, the expression of major histocompatibility complex molecules on IEC in some species has lead to the hypothesis that IEC can function as nonprofessional antigen-presenting cells (Christ and Blumberg, 1997; Perera et al., 2007). However, major histocompatibility complex II is not present on porcine IEC (Dvorak et al., 1987; Schierack et al., 2005). Therefore, at least in pigs, the role of IEC as an antigen-presenting cell may not be applicable.

As regulators of the immune response, there is evidence to indicate that IEC have mechanisms to avoid deleterious immune responses while retaining the ability to mediate an adaptive immune response. As mentioned previously, IEC are constantly bathed with commensal and pathogenic bacteria. Toll-like receptor recognition and expression patterns may help the gut to be tolerant of the antigenic load within the GIT. One example is underlined by the specificity and expression of Toll-like receptor 5. Toll-like receptor 5 is specific for bacterial flagellin and its expression is highly polarized to the basolateral surface of IEC (Gewirtz et al., 2001). Therefore, not only is Toll-like receptor 5 specific to a particular ligand, but ligand-receptor interactions may also occur only in the case of epithelial injury or bacterial invasion. Taken together, Toll-like receptors (and other pattern recognition receptors) are central to innate recognition and mucosal immunity, contribute to immune regulation, and lead to the initiation of adaptive immune responses (for reviews see Werling and Jungi, 2003; Pasare and Medzhitov, 2005).

With respect to IEC as targets of immune effectors, this role may be best described in the context of maintaining immune homeostasis and has been reviewed elsewhere (Shaykhiev and Bals, 2007). Briefly stated, this role for IEC may be described as a complex bidirectional relationship between IEC and leukocytes that contributes to homeostasis under normal conditions as well as during the development of disease.

\section{Implications for Growing Pigs}

Knowledge regarding the intricacies of mucosal immunity as it applies to the inductive and effector sites is particularly important in pigs because of the development of these sites as the pig matures. The neonatal pig is immunologically incompetent until about 4 wk of age (Blecha, 2001). Thus, the period from birth through weaning represents a critical time for pigs. During this period, the pig is exposed to and must mount appropriate immune responses toward or be tolerant of dietary and environmental antigens. Mucosal immunity, including the inductive and effector components of GALT, is extremely important in guiding the immune response toward an appropriate and effective immune response that strives to maintain intestinal homeostasis. Not only is the maintenance of intestinal homeostasis important for the development of the neonatal pig, but it also will most certainly have important ramifications for health and performance throughout the productive lifetime of the animal.

\section{LITERATURE CITED}

Andersen, J. K., H. Takamatsu, C. A. Oura, S. M. Brookes, L. Pullen, and R. E. Parkhouse. 1999. Systematic characterization of porcine ileal Peyer's patch, I. Apoptosis-sensitive immature B cells are the predominant cell type. Immunology 98:612-621.

Artis, D. 2008. Epithelial-cell recognition of commensal bacteria and maintenance of immune homeostasis in the gut. Nat. Rev. Immunol. 8:411-420.

Bailey, M., L. Hall, P. W. Bland, and C. R. Stokes. 1994. Production of cytokines by lymphocytes from spleen, mesenteric lymph node and intestinal lamina propria of pigs. Immunology $82: 577-583$.

Bailey, M., K. Haverson, C. Inman, C. Harris, P. Jones, G. Corfield, B. Miller, and C. Stokes. 2005. The influence of environment 
on development of the mucosal immune system. Vet. Immunol. Immunopathol. 108:189-198.

Bailey, M., F. J. Plunkett, H. J. Rothkotter, M. A. Vega-Lopez, K. Haverson, and C. R. Stokes. 2001. Regulation of mucosal immune responses in effector sites. Proc. Nutr. Soc. 60:427-435.

Binns, R. M., and S. T. Licence. 1985. Patterns of migration of labelled blood lymphocyte subpopulations: Evidence for two types of Peyer's patch in the young pig. Adv. Exp. Med. Biol. 186:661-668.

Blecha, F. 2001. Immunology. Pages 688-711 in Biology of the Domestic Pig. W. G. Pond and H. J. Mersmann, ed. Cornell Univ. Press, Ithaca, NY.

Bode, U., A. Sahle, G. Sparmann, F. Weidner, and J. Westermann. 2002. The fate of effector $\mathrm{T}$ cells in vivo is determined during activation and differs for $\mathrm{CD} 4^{+}$and $\mathrm{CD} 8^{+}$cells. J. Immunol. 169:6085-6091.

Brandtzaeg, P., I. N. Farstad, and L. Helgeland. 1998. Phenotypes of $\mathrm{T}$ cells in the gut. Chem. Immunol. 71:1-26.

Brandtzaeg, P., T. S. Halstensen, K. Kett, P. Krajci, D. Kvale, T. O. Rognum, H. Scott, and L. M. Sollid. 1989. Immunobiology and immunopathology of the human gut mucosa: Humoral immunity and intraepithelial lymphocytes. Gastroenterology 97:1562-1584.

Brandtzaeg, P., and R. Pabst. 2004. Let's go mucosal: Communication on slippery ground. Trends Immunol. 25:570-577.

Bucy, R. P., C. L. Chen, J. Cihak, U. Losch, and M. D. Cooper. 1988. Avian T cells expressing gamma delta receptors localize in the splenic sinusoids and the intestinal epithelium. J. Immunol. 141:2200-2205.

Butler, J. E., M. Sinkora, N. Wertz, W. Holtmeier, and C. D. Lemke. 2006b. Development of the neonatal B and T cell repertoire in swine: Implications for comparative and veterinary immunology. Vet. Res. 37:417-441.

Butler, J. E., J. Sun, N. Wertz, and M. Sinkora. 2006a. Antibody repertoire development in swine. Dev. Comp. Immunol. 30:199-221.

Cepek, K. L., S. K. Shaw, C. M. Parker, G. J. Russell, J. S. Morrow, D. L. Rimm, and M. B. Brenner. 1994. Adhesion between epithelial cells and T lymphocytes mediated by E-cadherin and the alpha E beta 7 integrin. Nature 372:190-193.

Christ, A. D., and R. S. Blumberg. 1997. The intestinal epithelial cell: Immunological aspects. Springer Semin. Immunopathol. 18:449-461.

Chu, R. M., and C. H. Liu. 1984. Morphological and functional comparisons of Peyer's patches in different parts of the swine small intestine. Vet. Immunol. Immunopathol. 6:391-403.

Dasso, J. F., and M. D. Howell. 1997. Neonatal appendectomy impairs mucosal immunity in rabbits. Cell. Immunol. 182:2937.

Dasso, J. F., H. Obiakor, H. Bach, A. O. Anderson, and R. G. Mage. 2000. A morphological and immunohistological study of the human and rabbit appendix for comparison with the avian bursa. Dev. Comp. Immunol. 24:797-814.

Dekaney, C. M., F. W. Bazer, and L. A. Jaeger. 1997. Mucosal morphogenesis and cytodifferentiation in fetal porcine small intestine. Anat. Rec. 249:517-523.

Didierlaurent, A., J. C. Sirard, J. P. Kraehenbuhl, and M. R. Neutra. 2002. How the gut senses its content. Cell. Microbiol. 4:61-72.

Dvorak, C. M., G. N. Hirsch, K. A. Hyland, J. A. Hendrickson, B. S. Thompson, M. S. Rutherford, and M. P. Murtaugh. 2006. Genomic dissection of mucosal immunobiology in the porcine small intestine. Physiol. Genomics 28:5-14.

Dvorak, P., V. Hruban, and V. Horak. 1987. The distribution of class II molecules in the pig intestine. Folia Morphol. (Praha) 35:396-399.

Eckmann, L. 2004. Innate immunity and mucosal bacterial interactions in the intestine. Curr. Opin. Gastroenterol. 20:82-88.

Eckmann, L., M. F. Kagnoff, and J. Fierer. 1993. Epithelial cells secrete the chemokine interleukin- 8 in response to bacterial entry. Infect. Immun. 61:4569-4574.
Eckmann, L., W. F. Stenson, T. C. Savidge, D. C. Lowe, K. E. Barrett, J. Fierer, J. R. Smith, and M. F. Kagnoff. 1997. Role of intestinal epithelial cells in the host secretory response to infection by invasive bacteria. Bacterial entry induces epithelial prostaglandin $\mathrm{h}$ synthase-2 expression and prostaglandin $\mathrm{E}_{2}$ and $\mathrm{F}_{2 \alpha}$ production. J. Clin. Invest. 100:296-309.

Elewaut, D., J. A. DiDonato, J. M. Kim, F. Truong, L. Eckmann, and M. F. Kagnoff. 1999. NF-kappa B is a central regulator of the intestinal epithelial cell innate immune response induced by infection with enteroinvasive bacteria. J. Immunol. 163:14571466 .

Falk, P. G., L. V. Hooper, T. Midtvedt, and J. I. Gordon. 1998. Creating and maintaining the gastrointestinal ecosystem: What we know and need to know from gnotobiology. Microbiol. Mol. Biol. Rev. 62:1157-1170.

Ganz, T. 2003. Defensins: Antimicrobial peptides of innate immunity. Nat. Rev. Immunol. 3:710-720.

Gebert, A., H. J. Rothkotter, and R. Pabst. 1996. M cells in Peyer's patches of the intestine. Int. Rev. Cytol. 167:91-159.

Gewirtz, A. T., and J. L. Madara. 2001. Periscope, up! Monitoring microbes in the intestine. Nat. Immunol. 2:288-290.

Gewirtz, A. T., T. A. Navas, S. Lyons, P. J. Godowski, and J. L. Madara. 2001. Cutting edge: Bacterial flagellin activates basolaterally expressed TLR5 to induce epithelial proinflammatory gene expression. J. Immunol. 167:1882-1885.

Gewirtz, A. T., A. S. Rao, P. O. Simon Jr., D. Merlin, D. Carnes, J. L. Madara, and A. S. Neish. 2000. Salmonella typhimurium induces epithelial IL-8 expression via $\mathrm{Ca}\left(2^{+}\right)$-mediated activation of the NF-kappaB pathway. J. Clin. Invest. 105:79-92.

Ghosh, S., M. J. May, and E. B. Kopp. 1998. NF-kappa B and Rel proteins: Evolutionarily conserved mediators of immune responses. Annu. Rev. Immunol. 16:225-260.

Goldsby, R. A., T. J. Kindt, B. A. Osborne, and J. Kuby. 2003. Immunology. 5th ed. W. H. Freeman and Co., New York, NY.

Goodman, T., and L. Lefrancois. 1988. Expression of the gammadelta T-cell receptor on intestinal $\mathrm{CD} 8^{+}$intraepithelial lymphocytes. Nature 333:855-858.

Gorbach, S. L., L. Nahas, P. I. Lerner, and L. Weinstein. 1967. Studies of intestinal microflora. I. Effects of diet, age, and periodic sampling on numbers of fecal microorganisms in man. Gastroenterology 53:845-855.

Griebel, P. J., and W. R. Hein. 1996. Expanding the role of Peyer's patches in B-cell ontogeny. Immunol. Today 17:30-39.

Gumbiner, B. 1987. Structure, biochemistry, and assembly of epithelial tight junctions. Am. J. Physiol. 253:C749-C758.

Hamada, H., T. Hiroi, Y. Nishiyama, H. Takahashi, Y. Masunaga, S. Hachimura, S. Kaminogawa, H. Takahashi-Iwanaga, T. Iwanaga, H. Kiyono, H. Yamamoto, and H. Ishikawa. 2002. Identification of multiple isolated lymphoid follicles on the antimesenteric wall of the mouse small intestine. J. Immunol. 168:57-64.

Hapfelmeier, S., B. Stecher, M. Barthel, M. Kremer, A. J. Muller, M. Heikenwalder, T. Stallmach, M. Hensel, K. Pfeffer, S. Akira, and W. D. Hardt. 2005. The Salmonella pathogenicity island (SPI)-2 and SPI-1 type III secretion systems allow Salmonella serovar typhimurium to trigger colitis via MyD88-dependent and MyD88-independent mechanisms. J. Immunol. 174:16751685.

Harriman, G. R., E. Hornqvist, and N. Y. Lycke. 1992. Antigenspecific and polyclonal $\mathrm{CD} 4^{+}$lamina propria T-cell lines: Phenotypic and functional characterization. Immunology 75:66-73.

Haverson, K., M. Bailey, and C. R. Stokes. 1999. T-cell populations in the pig intestinal lamina propria: Memory cells with unusual phenotypic characteristics. Immunology 96:66-73.

Havran, W. L., J. M. Jameson, and D. A. Witherden. 2005. Epithelial cells and their neighbors. III. Interactions between intraepithelial lymphocytes and neighboring epithelial cells. Am. J. Physiol. Gastrointest. Liver Physiol. 289:G627-G630.

Hayday, A., E. Theodoridis, E. Ramsburg, and J. Shires. 2001. Intraepithelial lymphocytes: Exploring the third way in immunology. Nat. Immunol. 2:997-1003. 
Heel, K. A., R. D. McCauley, J. M. Papadimitriou, and J. C. Hall. 1997. Review: Peyer's patches. J. Gastroenterol. Hepatol. 12:122-136.

Hokari, R., S. Miura, H. Nagata, H. Fujimori, S. Koseki, S. Kato, I. Kurose, E. Sekizuka, D. N. Granger, and H. Ishii. 2001. Intercellular cell adhesion molecule-1 regulates lymphocyte movement into intestinal microlymphatics of rat Peyer's patches. J. Leukoc. Biol. 70:896-902.

Hunyady, B., E. Mezey, and M. Palkovits. 2000. Gastrointestinal immunology: Cell types in the lamina propria-A morphological review. Acta Physiol. Hung. 87:305-328.

Hyland, K. A., L. Kohrt, L. Vulchanova, and M. P. Murtaugh. 2006. Mucosal innate immune response to intragastric infection by Salmonella enterica serovar Choleraesuis. Mol. Immunol. 43:1890-1899.

James, S. P. 1993. The gastrointestinal mucosal immune system. Dig. Dis. 11:146-156.

Jung, H. C., L. Eckmann, S. K. Yang, A. Panja, J. Fierer, E. Morzycka-Wroblewska, and M. F. Kagnoff. 1995. A distinct array of proinflammatory cytokines is expressed in human colon epithelial cells in response to bacterial invasion. J. Clin. Invest. 95:55-65.

Kagnoff, M. F. 1993. Immunology of the intestinal tract. Gastroenterology 105:1275-1280.

Kanamori, Y., K. Ishimaru, M. Nanno, K. Maki, K. Ikuta, H. Nariuchi, and H. Ishikawa. 1996. Identification of novel lymphoid tissues in murine intestinal mucosa where clusters of c-kit ${ }^{+}$IL$7 \mathrm{R}^{+}$Thy $1^{+}$lympho-hemopoietic progenitors develop. J. Exp. Med. 184:1449-1459.

Kaser, T., W. Gerner, S. E. Hammer, M. Patzl, and A. Saalmuller. 2008. Phenotypic and functional characterisation of porcine CD4(+)CD25(high) regulatory T cells. Vet. Immunol. Immunopathol. 122:153-158.

Lorenz, R. G., and R. D. Newberry. 2004. Isolated lymphoid follicles can function as sites for induction of mucosal immune responses. Ann. N. Y. Acad. Sci. 1029:44-57.

Lowden, S., and T. Heath. 1994. Ileal Peyer's patches in pigs: Intercellular and lymphatic pathways. Anat. Rec. 239:297-305.

Maaser, C., and M. F. Kagnoff. 2002. Role of the intestinal epithelium in orchestrating innate and adaptive mucosal immunity. Z. Gastroenterol. 40:525-529.

Makala, L. H., T. Kamada, H. Nagasawa, I. Igarashi, K. Fujisaki, N. Suzuki, T. Mikami, K. Haverson, M. Bailey, C. R. Stokes, and P. W. Bland. 2001. Ontogeny of pig discrete Peyer's patches: Expression of surface antigens. J. Vet. Med. Sci. 63:625-636.

Makala, L. H., N. Suzuki, and H. Nagasawa. 2002. Peyer's patches: Organized lymphoid structures for the induction of mucosal immune responses in the intestine. Pathobiology 70:55-68.

Mayer, L. 2000. Mucosal immunity and gastrointestinal antigen processing. J. Pediatr. Gastroenterol. Nutr. 30(Suppl.):S4-S12.

Mayrhofer, G. 1984. Physiology of the intestinal immune system. Pages 1-96 in Local Immune Responses of the Gut. T. J. Newby and C. R. Stokes, ed. CRC Press, Boca Raton, FL.

Medzhitov, R., P. Preston-Hurlburt, E. Kopp, A. Stadlen, C. Chen, S. Ghosh, and C. A. Janeway Jr. 1998. MyD88 is an adaptor protein in the hToll/IL-1 receptor family signaling pathways. Mol. Cell 2:253-258.

Meylan, E., J. Tschopp, and M. Karin. 2006. Intracellular pattern recognition receptors in the host response. Nature 442:39-44.

Moghaddami, M., A. Cummins, and G. Mayrhofer. 1998. Lymphocyte-filled villi: Comparison with other lymphoid aggregations in the mucosa of the human small intestine. Gastroenterology 115:1414-1425.

Mowat, A. M., and J. L. Viney. 1997. The anatomical basis of intestinal immunity. Immunol. Rev. 156:145-166.

Myer, M. S. 1982. The presence of Paneth cells confirmed in the pig. Onderstepoort J. Vet. Res. 49:131-132.

Nagler-Anderson, C. 2001. Man the barrier! Strategic defences in the intestinal mucosa. Nat. Rev. Immunol. 1:59-67.
Neutra, M. R., N. J. Mantis, and J. P. Kraehenbuhl. 2001. Collaboration of epithelial cells with organized mucosal lymphoid tissues. Nat. Immunol. 2:1004-1009.

Obremski, K., M. Gajecka, L. Zielonka, E. Jakimiuk, and M. Gajecki. 2005. Morphology and ultrastructure of small intestine mucosa in gilts with zearalenone mycotoxicosis. Pol. J. Vet. Sci. 8:301-307.

Oswald, I. P. 2006. Role of intestinal epithelial cells in the innate immune defence of the pig intestine. Vet. Res. 37:359-368.

Owen, R. L., and A. L. Jones. 1974. Epithelial cell specialization within human Peyer's patches: An ultrastructural study of intestinal lymphoid follicles. Gastroenterology 66:189-203.

Pabst, O., H. Herbrand, T. Worbs, M. Friedrichsen, S. Yan, M. W. Hoffmann, H. Korner, G. Bernhardt, R. Pabst, and R. Forster. 2005. Cryptopatches and isolated lymphoid follicles: Dynamic lymphoid tissues dispensable for the generation of intraepithelial lymphocytes. Eur. J. Immunol. 35:98-107.

Pabst, R., M. Geist, H. J. Rothkotter, and F. J. Fritz. 1988. Postnatal development and lymphocyte production of jejunal and ileal Peyer's patches in normal and gnotobiotic pigs. Immunology 64:539-544.

Pabst, R., and H. J. Rothkotter. 1999. Postnatal development of lymphocyte subsets in different compartments of the small intestine of piglets. Vet. Immunol. Immunopathol. 72:167-173.

Par, A. 2000. Gastrointestinal tract as a part of immune defence. Acta Physiol. Hung. 87:291-304.

Parng, C. L., S. Hansal, R. A. Goldsby, and B. A. Osborne. 1996. Gene conversion contributes to Ig light chain diversity in cattle. J. Immunol. 157:5478-5486.

Pasare, C., and R. Medzhitov. 2005. Toll-like receptors: Linking innate and adaptive immunity. Adv. Exp. Med. Biol. 560:1118.

Perera, L., L. Shao, A. Patel, K. Evans, B. Meresse, R. Blumberg, D. Geraghty, V. Groh, T. Spies, B. Jabri, and L. Mayer. 2007. Expression of nonclassical class I molecules by intestinal epithelial cells. Inflamm. Bowel Dis. 13:298-307.

Philpott, D. J., S. E. Girardin, and P. J. Sansonetti. 2001. Innate immune responses of epithelial cells following infection with bacterial pathogens. Curr. Opin. Immunol. 13:410-416.

Pitman, R. S., and R. S. Blumberg. 2000. First line of defense: The role of the intestinal epithelium as an active component of the mucosal immune system. J. Gastroenterol. 35:805-814.

Pospisil, R., and R. G. Mage. 1998. Rabbit appendix: A site of development and selection of the B cell repertoire. Curr. Top. Microbiol. Immunol. 229:59-70.

Rescigno, M., M. Urbano, B. Valzasina, M. Francolini, G. Rotta, R. Bonasio, F. Granucci, J. P. Kraehenbuhl, and P. RicciardiCastagnoli. 2001. Dendritic cells express tight junction proteins and penetrate gut epithelial monolayers to sample bacteria. Nat. Immunol. 2:361-367.

Reynolds, J. D. 1987. Peyer's patches and the early development of B lymphocytes. Curr. Top. Microbiol. Immunol. 135:43-56.

Rothkotter, H. J., H. J. Zimmermann, and R. Pabst. 1990. Size of jejunal Peyer's patches and migration of lymphocyte subsets in pigs after resection or transposition of the continuous ileal Peyer's patch. Scand. J. Immunol. 31:191-197.

Sang, Y., and F. Blecha. 2008. Porcine host defense peptides: Expanding repertoire and functions. Dev. Comp. Immunol. 33:334-343.

Sang, Y., A. A. Patil, G. Zhang, C. R. Ross, and F. Blecha. 2006. Bioinformatic and expression analysis of novel porcine betadefensins. Mamm. Genome 17:332-339.

Schantz, L. D., K. Laber-Laird, S. Bingel, and M. Swindle. 1996. Pigs: Applied anatomy of the gastrointestinal tract. Pages 2611-2619 in Essentials of Experimental Surgery: Gastroenterology. S. L. Jensen, H. Gregersen, F. Moody, and M. H. Shoouh-Amiri, ed. Harwood Academic Publishers, New York, NY.

Scharek, L., and K. Tedin. 2007. The porcine immune systemDifferences compared to man and mouse and possible conse- 
quences for infections by Salmonella serovars. Berl. Munch. Tierarztl. Wochenschr. 120:347-354.

Schierack, P., M. Nordhoff, M. Pollmann, K. D. Weyrauch, S. Amasheh, U. Lodemann, J. Jores, B. Tachu, S. Kleta, A. Blikslager, K. Tedin, and L. H. Wieler. 2005. Characterization of a porcine intestinal epithelial cell line for in vitro studies of microbial pathogenesis in swine. Histochem. Cell Biol. 125:293305.

Shanahan, F., and G. C. O'Sullivan. 1997. Appendectomy, mucosal immunity, and colitis. Gastroenterology 112:1766-1767.

Shaykhiev, R., and R. Bals. 2007. Interactions between epithelial cells and leukocytes in immunity and tissue homeostasis. J. Leukoc. Biol. 82:1-15.

Shen, L., and J. R. Turner. 2006. Role of epithelial cells in initiation and propagation of intestinal inflammation. Eliminating the static: Tight junction dynamics exposed. Am. J. Physiol. Gastrointest. Liver Physiol. 290:G577-G582.

Shimosato, T., M. Tohno, H. Kitazawa, S. Katoh, K. Watanabe, Y. Kawai, H. Aso, T. Yamaguchi, and T. Saito. 2005. Toll-like receptor 9 is expressed on follicle-associated epithelia containing M cells in swine Peyer's patches. Immunol. Lett. 98:83-89.

Simic, V., and A. Ilic. 1976. Essential comparative, morphological and topographical differences and characteristics of the cecum in man and domestic animals. Acta Anat. (Basel) 94:299310.

Skjolaas, K. A., T. E. Burkey, S. S. Dritz, and J. E. Minton. 2006. Effects of Salmonella enterica serovars Typhimurium (ST) and Choleraesusis (SC) on chemokine and cytokine expression in swine ileum and jejunal epithelial cells. Vet. Immunol. Immunopathol. 111:199-209.

Somekh, E., F. Serour, A. Gorenstein, M. Vohl, and D. Lehman. 2000. Phenotypic pattern of B cells in the appendix: Reduced intensity of CD19 expression. Immunobiology 201:461-469.

Spencer, J., T. Finn, and P. G. Isaacson. 1985. Gut associated lymphoid tissue: A morphological and immunocytochemical study of the human appendix. Gut 26:672-679.

Stokes, C. R., M. Bailey, and K. Haverson. 2001. Development and Function of the Pig Gastrointestinal Immune System. Pages 59-66 in Digestive Physiology of Pigs. J. E. Lindberg and B. Ogle, ed. CAB Int., New York, NY.

Stokes, C. R., M. Bailey, and A. D. Wilson. 1994. Immunology of the porcine gastrointestinal tract. Vet. Immunol. Immunopathol. 43:143-150.

Suau, A., R. Bonnet, M. Sutren, J. J. Godon, G. R. Gibson, M. D. Collins, and J. Dore. 1999. Direct analysis of genes encoding $16 \mathrm{~S}$ rRNA from complex communities reveals many novel molecular species within the human gut. Appl. Environ. Microbiol. 65:4799-4807.

Suzuki, K., T. Oida, H. Hamada, O. Hitotsumatsu, M. Watanabe, T. Hibi, H. Yamamoto, E. Kubota, S. Kaminogawa, and H. Ishikawa. 2000. Gut cryptopatches: Direct evidence of extrathymic anatomical sites for intestinal $\mathrm{T}$ lymphopoiesis. Immunity 13:691-702.

Takeda, K., and S. Akira. 2003. Toll receptors and pathogen resistance. Cell. Microbiol. 5:143-153.
Tohno, M., T. Shimazu, H. Aso, A. Uehara, H. Takada, A. Kawasaki, Y. Fujimoto, K. Fukase, T. Saito, and H. Kitazawa. 2008a. Molecular cloning and functional characterization of porcine nucleotide-binding oligomerization domain-1 (NOD1) recognizing minimum agonists, meso-diaminopimelic acid and mesolanthionine. Mol. Immunol. 45:1807-1817.

Tohno, M., T. Shimosato, H. Kitazawa, S. Katoh, I. D. Iliev, T. Kimura, Y. Kawai, K. Watanabe, H. Aso, T. Yamaguchi, and T. Saito. 2005. Toll-like receptor 2 is expressed on the intestinal M cells in swine. Biochem. Biophys. Res. Commun. 330:547554.

Tohno, M., W. Ueda, Y. Azuma, T. Shimazu, S. Katoh, J. M. Wang, H. Aso, H. Takada, Y. Kawai, T. Saito, and H. Kitazawa. 2008b. Molecular cloning and functional characterization of porcine nucleotide-binding oligomerization domain-2 (NOD2). Mol. Immunol. 45:194-203.

Turner, J. R. 2003. Functional morphology of the intestinal mucosae: From crypts to tips. Pages 1-22 in Microbial Pathogenesis and the Intestinal Epithelial Cell. G. Hecht, ed. ASM Press, Washington, DC.

Tyrer, P., A. R. Foxwell, A. W. Cripps, M. A. Apicella, and J. M. Kyd. 2006. Microbial pattern recognition receptors mediate M-cell uptake of a gram-negative bacterium. Infect. Immun. 74:625-631.

Uenishi, H., and H. Shinkai. 2008. Porcine Toll-like receptors: The front line of pathogen monitoring and possible implications for disease resistance. Dev. Comp. Immunol. In press.

Vega-Lopez, M. A., G. Arenas-Contreras, M. Bailey, S. GonzalezPozos, C. R. Stokes, M. G. Ortega, and R. Mondragon-Flores. 2001. Development of intraepithelial cells in the porcine small intestine. Dev. Immunol. 8:147-158.

Vega-Lopez, M. A., E. Telemo, M. Bailey, K. Stevens, and C. R. Stokes. 1993. Immune cell distribution in the small intestine of the pig: Immunohistological evidence for an organized compartmentalization in the lamina propria. Vet. Immunol. Immunopathol. 37:49-60.

Vora, P., A. Youdim, L. S. Thomas, M. Fukata, S. Y. Tesfay, K. Lukasek, K. S. Michelsen, A. Wada, T. Hirayama, M. Arditi, and M. T. Abreu. 2004. Beta-defensin-2 expression is regulated by TLR signaling in intestinal epithelial cells. J. Immunol. 173:5398-5405.

Werling, D., and T. W. Jungi. 2003. Toll-like receptors linking innate and adaptive immune response. Vet. Immunol. Immunopathol. 91:1-12.

Wittig, B. M., and M. Zeitz. 2003. The gut as an organ of immunology. Int. J. Colorectal Dis. 18:181-187.

Zhang, G., H. Wu, J. Shi, T. Ganz, C. R. Ross, and F. Blecha. 1998. Molecular cloning and tissue expression of porcine betadefensin-1. FEBS Lett. 424:37-40.

Zhu, J., K. Lai, R. Brownile, L. A. Babiuk, and G. K. Mutwiri. 2008. Porcine TLR 8 and TLR7 are both activated by a selective TLR7 ligand, imiquimod. Mol. Immunol. 45:3238-3243. 